\title{
A minimally invasive approach is more cost-effective than a traditional sternotomy approach for mitral valve surgery
}

\author{
Alexander Iribarne, MD, MS, ${ }^{a}$ Rachel Easterwood, BA, ${ }^{a}$ Mark J. Russo, MD, MS, ${ }^{\mathrm{b}}$ Y. Claire Wang, MD, \\ $\mathrm{ScD},{ }^{\mathrm{c}}$ Jonathan Yang, MD, ${ }^{\mathrm{a}}$ Kimberly N. Hong, MHSA, ${ }^{\mathrm{a}}$ Craig R. Smith, MD, ${ }^{\mathrm{a}}$ and \\ Michael Argenziano, $\mathrm{MD}^{\mathrm{a}}$
}

Objective: The aim of this study was to compare the cost and effectiveness of a minimally invasive (MI) versus traditional sternotomy (ST) approach for mitral valve surgery (MVS).

\begin{abstract}
Methods: From January 1, 2003, to December 31, 2008, a total of 847 patients underwent isolated MVS at our institution. Propensity matching on 22 clinical variables was carried out to generate a study cohort of 434 patients (217 matched pairs). Direct and indirect costs from the hospital perspective were retrospectively obtained from our finance department. Total hospital costs were further stratified into 13 standardized institutional billing categories. In addition, data on morbidity, mortality, discharge location, hospital readmissions within 1 year, and freedom from reoperation were obtained.
\end{abstract}

Results: Compared with ST, MIMVS was associated with a $\$ 9054 \pm \$ 3302$ lower mean total hospital cost $(P=.006)$, driven largely by a reduction in direct $(P=.003)$ versus indirect costs $(P=.06)$. Among the 13 billing categories, MIMVS was associated with a significant reduction in costs of cardiac imaging ( $P=.004)$, laboratory tests $(P=.005)$, boarding and nursing $(P=.001)$, and radiology $(P=.002)$. More patients in the ST group required intubation for more than 72 hours $(P=.019)$; however, there were no differences in morbidity or long-term survival $(P=.334)$. A higher proportion of MI patients were discharged home with no nursing services $(P=.018)$, and a higher proportion of ST patients required readmission within 1 year $(P=.023)$. There were no differences in freedom from reoperation between groups $(P=.574)$.

Conclusions: With equivalent efficacy across a range of measures and lower costs compared with ST, MIMVS represents a cost-saving strategy for MVS. (J Thorac Cardiovasc Surg 2011;142:1507-14)

During the past 10 years, there has been an increase in the number of studies on outcomes of minimally invasive mitral valve surgery (MIMVS). ${ }^{1-4}$ Since the first description of MIMVS by Cohn and associates ${ }^{5}$ and Navia and Cosgrove ${ }^{6}$ in the mid-1990s, various minimally invasive (MI) approaches have been reported including the parasternal, hemisternotomy, minithoracotomy, and totally endoscopic approach. ${ }^{5-8}$ Despite the variation in surgical approaches, the shared goal of MIMVS is to provide a safe and effective option for mitral valve surgery (MVS) with the clinical benefits associated with a minimal access approach.

Some of the reported benefits of MIMVS include decreased postoperative pain, improved postoperative

\footnotetext{
From the Division of Cardiothoracic Surgery, ${ }^{\text {a }}$ Department of Surgery, College of Physicians and Surgeons, Columbia University, New York, NY; the Section of Cardiac and Thoracic Surgery, ${ }^{\text {b }}$ University of Chicago Medical Center, Chicago, Ill; and the Department of Health Policy and Management, ${ }^{\mathrm{c}}$ Mailman School of Public Health, Columbia University, New York, NY.

This work was supported in part by National Institutes of Health Training Grant 5T32HL007854-13 (to Dr Iribarne).

Disclosures: Authors have nothing to disclose with regard to commercial support. Received for publication Oct 3, 2010; revisions received March 20, 2011; accepted for publication April 11, 2011; available ahead of print June 13, 2011.

Address for reprints: Michael Argenziano, MD, Columbia University Medical Center, Milstein Hospital Building, Room 7-435, 177 Fort Washington Ave, New York, NY 10032 (E-mail: ma66@columbia.edu).

$0022-5223 / \$ 36.00$

Copyright (c) 2011 by The American Association for Thoracic Surgery doi:10.1016/j.jtcvs.2011.04.038
}

respiratory function, reduced surgical trauma, and improved cosmesis and patient satisfaction. ${ }^{9-11}$ In addition, other reported benefits include decreased intensive care unit and total hospital length of stay, faster physical rehabilitation, and decreased overall hospital resource use. $^{5,12-14}$

These reported benefits have often been tempered by concerns regarding the safety and durability of an MI approach, the potential disadvantages of decreased surgical exposure, and the potential for increased operative times. Although there are currently no prospective, randomized trials comparing an MI to a sternotomy (ST) approach for MVS, several single-institution studies have confirmed that many of the proposed benefits of MIMVS can be achieved with no detrimental effects on morbidity, mortality, or long-term valve function. ${ }^{15-18}$

Although early studies have suggested lower hospital costs associated with MIMVS, ${ }^{7,19,20}$ no studies in the past decade have specifically performed a detailed economic evaluation of this approach. In this analysis we assess the cost-effectiveness of an MI versus an ST approach for MVS.

\section{METHODS AND PATIENTS \\ Study Population}

From January 1, 2003, to December 31, 2008, a total of 847 patients underwent isolated MVS at our institution. After obtaining institutional 


$$
\begin{aligned}
& \text { Abbreviations and Acronyms } \\
& \begin{aligned}
\text { MI } & =\text { minimally invasive } \\
\text { MIMVS } & =\text { minimally invasive mitral valve } \\
& \text { surgery } \\
\text { MVS } & =\text { mitral valve surgery } \\
\text { ST } & =\text { sternotomy }
\end{aligned}
\end{aligned}
$$

review board approval, we retrospectively gathered data on patient demographics, hospital costs, operative parameters, and both short- and long-term morbidity and mortality using data from our hospital finance department, institutional medical records, and operative reports that comprise our internal cardiac surgery registry, as well as data from the New York State Cardiac Surgery Database. ${ }^{21}$

Isolated MVS was defined as any mitral valve repair or replacement performed in the absence of a major concomitant procedure such as coronary artery bypass grafting or other valve surgery. A total of 209 (24.7\%) patients underwent minor concomitant procedures including atrial fibrillation ablation $(n=149,17.6 \%)$ and atrial septal defect repair $(n=60,7.1 \%)$. There were 316 mitral valve replacements $(37.3 \%)$ and 531 mitral valve repairs $(62.7 \%)$. A traditional median ST approach was used in 348 $(41.1 \%)$ patients and an MI approach was used in $499(58.9 \%)$ patients. Although MIMVS can be defined broadly as per Society of Thoracic Surgeons Database guidelines as any mitral valve repair or replacement performed through an incision other than a full median sternotomy, in our analysis MIMVS was isolated to either a minithoracotomy, which was used in the majority of cases, or a hemisternotomy approach. ${ }^{22}$ Robotic mitral valve surgery was not included in the analysis.

\section{Operative Technique}

Among the MIMVS cases, 496 (99.4\%) were performed through a right minithoracotomy and $3(0.6 \%)$ were performed through a hemisternotomy. Our operative approach for MIMVS performed through a minithoracotomy has been described previously. ${ }^{18}$ Of note, aortic cannulation was most commonly performed in a central fashion and venous drainage was most commonly achieved through a percutaneous femoral vein approach using single multistage venous cannulation. Central aortic cannulation was performed through the initial thoracotomy incision and a transthoracic aortic crossclamp (Chitwood) was passed through a stab wound in the right axilla. It has been our institutional preference to use a central approach for arterial cannulation to avoid the potential complications associated with peripheral cannulation such as arterial dissection, embolism, retroperitoneal hematoma, and wound infection.

Cost outcomes. The primary end point of the analysis was total hospital cost of the surgical admission. From the hospital perspective, we estimated total cost as all costs incurred from the time of operation to the time of hospital discharge, including intraoperative and postoperative costs. Hospital cost data were obtained from our institutional finance department decision support system (Eclipsys Transition System Incorporated, Atlanta, Ga), which provides audited clinical, financial, and operational data. ${ }^{23}$ Of note, the reported cost data represent actual resource costs to the hospital for services rendered rather than billed charges.

Total hospital cost was stratified into direct and indirect costs. Direct costs represent costs associated with providing services or products to the patient, such as laboratory tests, diagnostic imaging, medications, or surgical procedures. Indirect costs represent hospital administrative expenses not directly generated by patient care activities, such as facility maintenance and administration. Total hospital cost was also stratified into 13 standardized institutional billing categories, including blood bank, cardiac imaging, cardiac catheterization laboratory, dialysis, emergency room, laboratory, neurology, boarding and nursing, operating room, pharmacy, radiology, rehabilitation, and respiratory care.

Clinical outcomes. Both short- and long-term clinical outcomes were analyzed to assess the efficacy of MIMVS. Short-term outcomes included cardiopulmonary bypass time, crossclamp time, hospital length of stay, discharge location, and major in-hospital complications (ie, intubation greater than 72 hours, renal failure, sepsis, reoperation for bleeding, stroke less than 24 hours after surgery, stroke 24 hours or more after surgery, gastrointestinal bleeding, and transmural myocardial infarction). Long-term outcomes included survival, freedom from reoperation, and the number of medical or surgical readmissions occurring within 1 year of discharge. Reasons for readmissions were categorized into the following: cardiac surgery, pacemaker placement, percutaneous coronary intervention, arrhythmia, pleural effusion, neurologic, or other causes.

Propensity matching. To account for differences in baseline characteristics between groups, we used propensity score matching. A parsimonious model of risk factors for selection to an MI versus ST approach was created using 22 baseline patient characteristics and relevant operative variables including mitral repair versus replacement, presence of a concomitant procedure, and surgeon (Appendix 1). A stepwise logistic regression approach (backward, remove $P>.20$ ) was used for variable selection to create the final model (Appendix 2). From this model, propensity scores were generated for each patient. Propensity scores were then nearest neighbor matched 1:1 to create ST- and MI-matched pairs for analysis.

\section{Statistical Analysis}

Standard cost-effectiveness analyses are traditionally based on the difference in arithmetic mean cost. ${ }^{24}$ However, inasmuch as medical costs are usually right skewed, as costs cannot be negative, we reported both mean and median costs. For mean costs, we estimated associated bootstrapped standard errors, using 1000 iterations, and applied the nonparametric bootstrap $t$ test, again using 1000 iterations, to compare costs between groups. ${ }^{25}$ For median costs, results of the Wilcoxon rank sum test are reported. To assess the independent effect of multiple baseline variables (Appendix 1) and presence of complications on total hospital costs, we used generalized linear models. Variable selection for generalized linear models was performed via backward, stepwise regression (remove $P>$ .20); the traditional log-link function and gamma distribution we used as per the modified Parks test. ${ }^{26}$ Owing to the log transformation, regression coefficients are reported in exponentiated form to highlight the multiplicative effect of a unit change in the independent variable on total hospital cost.

For clinical data, continuous variables were reported as mean \pm standard error and were compared using the Student $t$ test or Wilcoxon rank sum test when noted. Categorical variables were reported as percentages and compared using the $\chi^{2}$ or Fisher's exact test when appropriate. Long-term survival and freedom from reoperation were assessed using the Kaplan-Meier method and were compared using the log-rank test. Survival data were obtained from the Social Security Death Index and provided through December 14, 2009. Follow-up freedom from reoperation data were obtained through June 1, 2010. All reported $P$ values are 2-sided. All statistical analyses were performed using Stata 10 (Stata Corp, College Station, Tex).

\section{RESULTS Study Population}

Between January 1, 2003, and December 31, 2008, 847 patients underwent isolated MVS at our institution. Table 1 summarizes the baseline characteristics of the original study population, with significant differences observed between MI and ST groups across most variables. The final model for propensity matching (Appendix 2) had an area under 
TABLE 1. Baseline characteristics of original study population

\begin{tabular}{lccc}
\hline & $\begin{array}{c}\text { ST } \\
(\mathbf{n}=\mathbf{3 4 8})\end{array}$ & $\begin{array}{c}\text { MI } \\
(\mathbf{n}=\mathbf{4 9 9})\end{array}$ & $\begin{array}{c}\boldsymbol{P} \\
\text { value }\end{array}$ \\
\hline Age & $63.2 \pm 0.82$ & $58.8 \pm 0.61$ & $<.0001$ \\
Body mass index & $26.6 \pm 0.33$ & $25.1 \pm 0.18$ & $<.0001$ \\
Cerebrovascular accident & $34(9.8 \%)$ & $21(4.2 \%)$ & .002 \\
Chronic obstructive pulmonary & $27(7.8 \%)$ & $21(4.2 \%)$ & .034 \\
$\quad$ disease & & & \\
Creatinine & $1.31 \pm 0.08$ & $0.97 \pm 0.02$ & $<.0001$ \\
Current congestive heart failure & $110(31.6 \%)$ & $70(14.0 \%)$ & $<.001$ \\
Current smoker & $13(3.7 \%)$ & $21(4.2 \%)$ & .859 \\
Diabetes & $41(11.8 \%)$ & $29(5.8 \%)$ & .002 \\
Ejection fraction (\%) & $48.9 \pm 0.61$ & $51.6 \pm 0.42$ & $<.001$ \\
Gender (male) & $192(55.2 \%)$ & $230(46.1 \%)$ & .009 \\
Hepatic failure & $1(0.29 \%)$ & $1(0.20 \%)$ & 1.0 \\
History of endocarditis & $15(4.3 \%)$ & $4(0.80 \%)$ & .098 \\
History of ventricular arrhythmias & $2(0.57 \%)$ & $2(0.40 \%)$ & 1.0 \\
Immune system deficiency & $22(6.3 \%)$ & $8(1.6 \%)$ & $<.001$ \\
Intra-aortic balloon pump & $4(1.1 \%)$ & 0 & .028 \\
Peripheral vascular disease & $9(2.6 \%)$ & $4(0.80 \%)$ & .047 \\
Previous myocardial infarction & $26(7.5 \%)$ & $27(5.4 \%)$ & .249 \\
Previous surgery & $99(28.5 \%)$ & $30(6.0 \%)$ & $<.001$ \\
Renal failure or dialysis & $14(4.0 \%)$ & $2(0.40 \%)$ & $<.001$ \\
Vasodilatory shock (preoperative) & $4(1.1 \%)$ & $1(0.20 \%)$ & .654 \\
\hline$S T$ Sten & & &
\end{tabular}

ST, Sternotomy; $M I$, minimally invasive.

the receiver operating characteristic curve of $0.813 \pm 0.025$, demonstrating good model discrimination.

A total of 217 matched pairs were generated for a resulting sample size of 434 patients or $51.2 \%$ of the original study population. Among the matched pairs, there were no significant differences in major baseline characteristics (Table 2).

\section{Operative Characteristics}

Among propensity matched MI patients, all mitral valve operations were performed through a right minithoracotomy. There was no difference in the proportion of repairs versus replacements $(P=.768)$, with mitral valve repair being more common than replacement among both ST and MI groups. Also, there was no difference in mitral valve disease $(P=.424)$ or mitral valve disease etiology $(P=.594)$ (Table 3). In addition, there was no difference in the proportion of concomitant procedures between groups $(P=.141)$. The cardiopulmonary bypass time was longer among MI patients by $24.6 \pm 4.1$ minutes $(P<.0001)$, but the crossclamp time did not differ between groups $(P=.135)$. Among MI patients, there were no conversions to a median ST approach.

\section{Cost Analysis}

The MI approach was associated with a $\$ 9,054 \pm \$ 3,302$ lower mean hospital cost of admission (ST: $\$ 50,060 \pm$ \$2659; MI: $\$ 41,006 \pm \$ 1887 ; P=.006$ ). When median cost was used, the reduction in total hospital cost was
TABLE 2. Baseline characteristics of matched pairs

\begin{tabular}{|c|c|c|c|}
\hline & $\begin{array}{c}\text { ST } \\
(n=217)\end{array}$ & $\begin{array}{c}\text { MI } \\
(n=217)\end{array}$ & $\begin{array}{c}P \\
\text { value }\end{array}$ \\
\hline Age (y) & $61.5 \pm 1.10$ & $59.3 \pm 0.94$ & .117 \\
\hline Body mass index & $25.7 \pm 0.38$ & $25.6 \pm 0.30$ & .819 \\
\hline Cerebrovascular accident & $19(8.8 \%)$ & $13(6.0 \%)$ & .359 \\
\hline $\begin{array}{l}\text { Chronic obstructive } \\
\text { pulmonary disease }\end{array}$ & $16(7.4 \%)$ & $10(4.6 \%)$ & .312 \\
\hline Creatinine (mg/dL) & $1.21 \pm 0.10$ & $1.02 \pm 0.05$ & .101 \\
\hline $\begin{array}{l}\text { Current congestive heart } \\
\text { failure }\end{array}$ & $51(23.5 \%)$ & $47(21.7 \%)$ & .731 \\
\hline Current smoker & $5(2.3 \%)$ & $11(5.1 \%)$ & .202 \\
\hline Diabetes & $17(7.8 \%)$ & $19(8.8 \%)$ & .862 \\
\hline Ejection fraction $(\%)$ & $49.7 \pm 0.78$ & $50.3 \pm 0.71$ & .576 \\
\hline Gender (male) & $111(51.2 \%)$ & $111(51.2 \%)$ & 1.0 \\
\hline Hepatic failure & $1(0.46 \%)$ & 0 & 1.0 \\
\hline History of endocarditis & $5(2.3 \%)$ & $3(1.4 \%)$ & .724 \\
\hline $\begin{array}{l}\text { History of ventricular } \\
\text { arrhythmias }\end{array}$ & $1(0.46 \%)$ & $1(0.46 \%)$ & 1.0 \\
\hline Immune system deficiency & $10(4.6 \%)$ & $7(3.2 \%)$ & .622 \\
\hline Intra-aortic balloon pump & $3(1.4 \%)$ & 0 & .248 \\
\hline Peripheral vascular disease & $2(0.92 \%)$ & $2(0.92 \%)$ & 1.0 \\
\hline $\begin{array}{l}\text { Previous myocardial } \\
\text { infarction }\end{array}$ & $18(8.3 \%)$ & $18(8.3 \%)$ & 1.0 \\
\hline Previous surgery & $26(12.0 \%)$ & $22(10.1 \%)$ & .647 \\
\hline Renal failure or dialysis & $5(2.3 \%)$ & $2(0.92 \%)$ & .449 \\
\hline $\begin{array}{l}\text { Vasodilatory shock } \\
\text { (preoperative) }\end{array}$ & $2(0.92 \%)$ & $1(0.46 \%)$ & 1.0 \\
\hline
\end{tabular}

$S T$, Sternotomy; $M I$, minimally invasive.

$\$ 3595$ (ST: $\$ 37,013$; MI: $\$ 33,418 ; P=.003$ ). The MI approach was also associated with a $\$ 5993 \pm \$ 2008$ lower mean direct cost (ST: $\$ 29,273 \pm \$ 1610$; MI: $\$ 23,279 \pm$ $\$ 1207 ; P=.003)$, but there was no difference in mean indirect cost between groups (ST: $\$ 20,787 \pm \$ 1320 ;$ MI: $\$ 17,727$ $\pm \$ 993 ; P=.06$ ) (Figure 1 ). When median cost was used, the reduction in direct cost was $\$ 3270$ (ST: $\$ 21,674$; MI: $\$ 18,404 ; P=.001)$ and the reduction in indirect cost was $\$ 1896$ (ST: $\$ 15,185 ;$ MI: $\$ 13,289 ; P=.023$ ). Among our institutional billing categories (Table 4), the lower cost of the MI approach was primarily driven by a reduction in cost of boarding and nursing $(P=.001)$. There was a significant positive correlation between hospital length of stay and the cost of boarding and nursing (0.923 [0.912-0.932]; $P<.0001)$. Lower costs were also observed among MI patients in the categories of cardiac imaging $(P=.004)$, laboratory tests $(P=.005)$, and radiology $(P=.002)$.

In multivariable analysis, age $(P=.003)$, diabetes $(P=.039)$, and previous surgery $(P=.001)$, as well as intubation for more than 72 hours $(P<.001)$ and sepsis $(P=.03)$ were associated with higher total hospital costs among MI patients. Among ST patients, peripheral vascular disease $(P=.036)$, intubation for more than 72 hours $(P<.001)$, and reoperation $(P=.005)$ were associated with higher costs (Table 5). 
TABLE 3. Operative characteristics of matched pairs

\begin{tabular}{|c|c|c|c|}
\hline & $\begin{array}{c}\text { ST } \\
(n=217)\end{array}$ & $\begin{array}{c}\text { MI } \\
(n=217)\end{array}$ & $\begin{array}{c}P \\
\text { value }\end{array}$ \\
\hline \multicolumn{4}{|l|}{ Mitral valve surgery type } \\
\hline Replacement & $87(40.1 \%)$ & $83(38.3 \%)$ & .768 \\
\hline Repair & $130(59.9 \%)$ & $134(61.8 \%)$ & \\
\hline \multicolumn{4}{|l|}{ Mitral valve disease } \\
\hline Mitral regurgitation & $185(85.3 \%)$ & $183(84.3 \%)$ & .424 \\
\hline Mitral stenosis & $24(11.1 \%)$ & $30(13.8 \%)$ & \\
\hline \multicolumn{4}{|l|}{ Mitral valve disease etiology } \\
\hline Degenerative & $130(59.9 \%)$ & $128(59.0 \%)$ & .594 \\
\hline Anterior leaflet prolapse & $28(12.9 \%)$ & $16(7.4 \%)$ & \\
\hline Bileaflet prolapse & $21(9.7 \%)$ & $33(15.2 \%)$ & \\
\hline Posterior leaflet prolapse & $81(37.3 \%)$ & $79(36.4 \%)$ & \\
\hline Dilated cardiomyopathy & $13(6.0 \%)$ & $10(4.6 \%)$ & \\
\hline Endocarditis & $19(8.8 \%)$ & $14(6.5 \%)$ & \\
\hline Ischemic & $9(4.2 \%)$ & $15(6.9 \%)$ & \\
\hline Rheumatic & $17(7.8 \%)$ & $25(11.5 \%)$ & \\
\hline Calcific & $22(10.1 \%)$ & $20(9.2 \%)$ & \\
\hline Other & $7(3.2 \%)$ & $5(2.3 \%)$ & \\
\hline \multicolumn{4}{|l|}{ Concomitant procedures } \\
\hline Atrial septal defect repair & $14(6.5 \%)$ & $18(8.3 \%)$ & .141 \\
\hline Atrial fibrillation ablation & $50(23.0 \%)$ & $32(14.7 \%)$ & \\
\hline \multicolumn{4}{|l|}{ Operative times (min) } \\
\hline CPB time & $112.6 \pm 2.2$ & $137.3 \pm 3.4$ & $<.0001$ \\
\hline Crossclamp time & $75.8 \pm 1.6$ & $80.7 \pm 2.8$ & .135 \\
\hline
\end{tabular}

$S T$, Sternotomy; $M I$, minimally invasive; $C P B$, cardiopulmonary bypass.

\section{Clinical Outcomes}

The mean length of stay was approximately 2 days shorter among MI patients than ST patients (MI: $7.12 \pm$ 0.36 days; ST: $9.19 \pm 0.52$ days; $P=.001$ ). The difference in median lengths of stay for MI and ST patients was also statistically significant (MI: 6 days; ST: 7 days; $P=.0001)$. In terms of postoperative complications, there were no significant differences in gastrointestinal bleeding

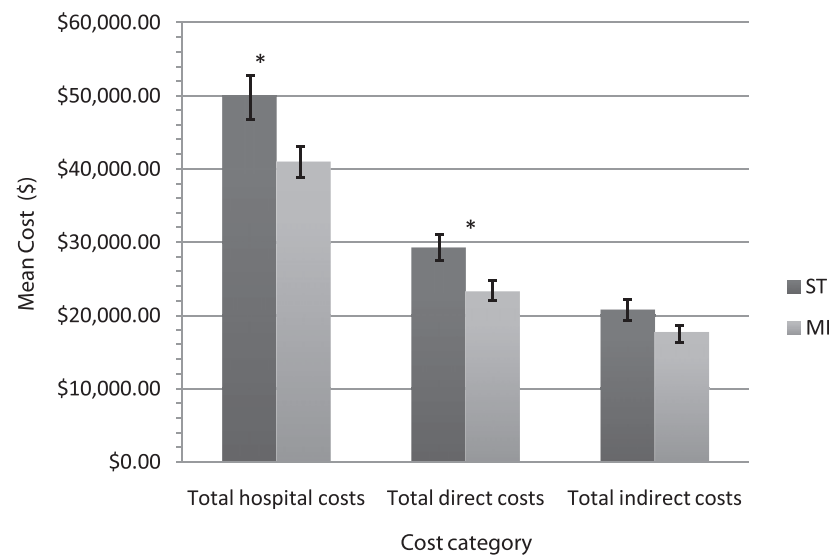

FIGURE 1. Total and stratified hospital costs with bootstrapped standard error estimates. ST, Sternotomy; $M I$, minimally invasive. *Statistically significant difference between groups.
( $P=1.0)$, renal failure $(P=.284)$, reoperation for bleeding $(P=.544)$, sepsis $(P=1.0)$, stroke less than 24 hours after surgery $(P=.623)$, stroke 24 hours or more after surgery $(P=.685)$, or transmural myocardial infarction $(P=1.0)$. There was, however, a greater proportion of patients in the ST group who required intubation for more than 72 hours: ST: $8.3 \%(\mathrm{n}=18)$, MI: $2.8 \%(\mathrm{n}=6): P=.019$. The mean duration of survival follow-up was $3.2 \pm 1.6$ years. There was no difference in survival at 30 days $(P=.503)$ or 1 -year $(P=.827)$ between groups. There was also no significant difference in long-term survival $(P=.334)$.

There was a significant difference in the distribution of discharge locations between MI and ST patients $(P=.018)$ (Table 6). A higher proportion of MI patients $(66.8 \%, \mathrm{n}=135)$ were discharged home with no nursing services compared with ST $(54.4 \%, \mathrm{n}=111)$, whereas a higher proportion of ST patients were discharged home with a nursing aide $(30.9 \%, \mathrm{n}=63)$ compared with MI $(25.7 \%, \mathrm{n}=52)$. In addition, a higher proportion of ST patients $(14.7 \%, \mathrm{n}=30)$ were discharged to rehabilitation facilities when compared with MI patients $(7.5 \%, \mathrm{n}=15)$.

Hospital readmissions within 1 year of surgery were also studied between groups, and there were a higher proportion of readmissions among ST patients (ST: $13.7 \%, \mathrm{n}=28$; MI: $6.8 \%, \mathrm{n}=14 ; P=.023)$. In both groups, the most common cause for readmission was arrhythmias managed medically (Table 6). With regard to freedom from reoperation, there was no significant difference between groups $(P=.574)$ (Figure 2). The average duration of follow-up was $4.5 \pm 1.7$ years.

\section{DISCUSSION}

Over the past 2 years, there has been a growth of interest in the economic evaluation of new surgical technologies and techniques, coinciding with increased national attention to comparative effectiveness research. ${ }^{27,28}$ While early studies by Chitwood, ${ }^{7,19} \mathrm{Cohn},{ }^{5}$ Cosgrove,${ }^{20}$ and their associates in the 1990 s reported $7 \%$ to $34 \%$ cost savings associated with MIMVS, no studies in the past decade have specifically compared costs between MI and ST approaches as a primary end point.

In our analysis, patients undergoing MIMVS had a $\$ 9054$ lower mean total cost of admission resulting in cost savings of $18 \%$ compared with the ST approach. In addition, we demonstrate that the difference in hospital cost between groups was largely driven by differences in direct rather than indirect costs. These results support the generalizability of our findings as direct costs involve costs related to patient care, whereas indirect costs represent costs attributable to hospital maintenance and utilities, which may vary from region to region.

The hypothesis that MIMVS could be cost saving has been driven largely by the observation that patients 
TABLE 4. Total hospital costs stratified by billing category

\begin{tabular}{|c|c|c|c|c|c|c|}
\hline \multirow[b]{2}{*}{ Cost category } & \multicolumn{3}{|c|}{ Mean cost } & \multicolumn{3}{|c|}{ Median cost } \\
\hline & ST $(n=217)$ & MI $(n=217)$ & $P$ value & ST $(n=217)$ & MI $(\mathbf{n}=217)$ & $P$ value \\
\hline Blood bank & $\$ 1426 \pm 131$ & $\$ 1605 \pm 238$ & .151 & $\$ 898$ & $\$ 585$ & .262 \\
\hline Cardiac imaging & $\$ 297 \pm 27$ & $\$ 201 \pm 19$ & .004 & $\$ 188$ & $\$ 56$ & .002 \\
\hline Cardiac catheterization & $\$ 4344 \pm 218$ & $\$ 4500 \pm 179$ & .588 & $\$ 4,165$ & $\$ 4343$ & .130 \\
\hline Dialysis & $\$ 5313 \pm 4649$ & $\$ 556 \pm 500$ & .487 & $\$ 1,361$ & $\$ 556$ & .564 \\
\hline Emergency room & $\$ 1452 \pm 214$ & $\$ 1032 \pm 296$ & .234 & $\$ 1,756$ & $\$ 324$ & .551 \\
\hline Laboratory tests & $\$ 1953 \pm 159$ & $\$ 1404 \pm 108$ & .004 & $\$ 1,282$ & $\$ 1006$ & $<.001$ \\
\hline Neurology & $\$ 1919 \pm 1451$ & $\$ 407 \pm 301$ & .309 & $\$ 127$ & $\$ 152$ & .952 \\
\hline Boarding and nursing & $\$ 21,950 \pm 1565$ & $\$ 15,798 \pm 1027$ & .001 & $\$ 13,367$ & $\$ 11,157$ & $<.001$ \\
\hline Operating room & $\$ 15,905 \pm 438$ & $\$ 15,984 \pm 322$ & .888 & $\$ 14,699$ & $\$ 14,874$ & .356 \\
\hline Pharmacy & $\$ 3157 \pm 413$ & $\$ 2668 \pm 275$ & .330 & $\$ 1,859$ & $\$ 1569$ & .064 \\
\hline Radiology & $\$ 1770 \pm 236$ & $\$ 954 \pm 97$ & .002 & $\$ 733$ & $\$ 608$ & .004 \\
\hline Rehabilitation & $\$ 853 \pm 98$ & $\$ 723 \pm 85$ & .344 & $\$ 591$ & $\$ 464$ & .005 \\
\hline Respiratory care & $\$ 1632 \pm 329$ & $\$ 1349 \pm 215$ & .466 & $\$ 578$ & $\$ 661$ & .464 \\
\hline
\end{tabular}

$S T$, Sternotomy; $M I$, minimally invasive.

undergoing MIMVS generally have a shorter length of stay. In a recent meta-analysis by Modi and associates, ${ }^{29} 8$ of 14 studies on MIMVS reported a shorter hospital stay when compared to the ST approach. ${ }^{30}$ We have previously reported a shorter length of stay among MIMVS patients. ${ }^{18}$ In this cohort, we estimated the difference was approximately 2 days on average. Notably, among our institutional billing categories we found significant differences in costs associated with boarding and nursing, laboratory tests, radiology, and cardiac imaging. As expected, there was a significant, positive correlation between length of stay and costs of boarding and nursing. Individuals in a hospital for fewer days will incur less boarding and nursing costs, and will also likely have lower costs associated with routine activities such as daily laboratory and imaging studies. In our

TABLE 5. Baseline patient characteristics and postoperative complications associated with total hospital costs significant in multivariable regression

\begin{tabular}{|c|c|c|c|}
\hline & $\begin{array}{c}\operatorname{Exp} \beta \\
\text { coefficient }\end{array}$ & $95 \%$ CI & $\begin{array}{c}P \\
\text { value }\end{array}$ \\
\hline \multicolumn{4}{|l|}{ Baseline patient characteristic } \\
\hline \multicolumn{4}{|l|}{ ST } \\
\hline Peripheral vascular disease & 2.41 & $1.06-5.45$ & .036 \\
\hline \multicolumn{4}{|l|}{ MI } \\
\hline Age & 1.01 & $1.00-1.02$ & .003 \\
\hline Diabetes & 1.39 & $1.02-1.90$ & .039 \\
\hline Previous surgery & 1.65 & $1.24-2.19$ & .001 \\
\hline \multicolumn{4}{|l|}{ Complications } \\
\hline \multicolumn{4}{|l|}{ ST } \\
\hline Intubation $>72 \mathrm{~h}$ & 3.06 & $2.25-4.16$ & $<.001$ \\
\hline Reoperation & 2.02 & $1.24-3.28$ & .005 \\
\hline \multicolumn{4}{|l|}{ MI } \\
\hline Intubation $>72 \mathrm{~h}$ & 2.64 & $1.64-4.26$ & $<.001$ \\
\hline Sepsis & 3.45 & $1.13-6.56$ & .03 \\
\hline
\end{tabular}

$C I$, Confidence interval; $S T$, sternotomy; $M I$, minimally invasive. multivariable analysis, intubation for more than 72 hours was a significant independent predictor of total hospital cost shared by both MI and ST groups. MI patients had a 5.5\% lower rate of this complication; however, the overall prevalence of this complication in the series was low. Thus, although our results demonstrate that the majority of cost savings associated with MIMVS occurred in the category of boarding and nursing, which results from a shorter length of stay, further research is necessary to determine the exact cause of the shorter hospitalization. In addition to shorter intubation times, other factors may include decreased postoperative pain and improved postoperative physical rehabilitation.

Also, it must be noted that although MI patients had a shorter length of stay than ST patients, the mean lengths of stay for MI and ST groups were 7.1 and 9.2 days, respectively. There is likely significant variability from one hospital to the next with respect to hospital stay. For example, Suri and associates ${ }^{30}$ reported lengths of stay of 6.95 days for port access patients and 6.19 days among ST patients who received mitral valve repairs. A recent executive summary of The Society of Thoracic Surgeons Adult Cardiac Surgery Database reported a mean length of stay of 10.5 days for all mitral valve replacements and 7 days for all mitral valve repairs performed in 2009. ${ }^{31}$ Gammie and associates $^{32}$ analyzed all less invasive mitral valve operations in The Society of Thoracic Surgeons Database from 2004 to 2008 and reported a 6.9-day risk-adjusted mean hospital stay for the less invasive group. ${ }^{31}$ Thus, hospital stays vary from one center to the next, and those reported in our analysis for MI and ST patients, which included both repairs and replacements, may be slightly higher than those observed in other centers. This variability may be explained by the fact that patients in our analysis had numerous comorbidities. For example, among propensity matched MIMVS patients, $22 \%$ had congestive heart failure, $8.8 \%$ 
TABLE 6. In-hospital complications, short-term survival, discharge location, and readmissions

\begin{tabular}{|c|c|c|c|}
\hline & $\begin{array}{c}\text { ST } \\
(n=217) \\
\end{array}$ & $\begin{array}{c}\text { MI } \\
(\mathbf{n}=\mathbf{2 1 7}) \\
\end{array}$ & $\begin{array}{c}P \\
\text { value }\end{array}$ \\
\hline \multicolumn{4}{|l|}{ Complications } \\
\hline Gastrointestinal bleed & $1(0.46 \%)$ & $1(0.46 \%)$ & 1.0 \\
\hline Intubation $>72 \mathrm{~h}$ & $18(8.3 \%)$ & $6(2.8 \%)$ & .019 \\
\hline Renal failure & $6(2.8 \%)$ & $2(0.92 \%)$ & .284 \\
\hline Reoperation for bleeding & $7(3.2 \%)$ & $4(1.8 \%)$ & .544 \\
\hline Sepsis & $2(0.92 \%)$ & $3(1.4 \%)$ & 1.0 \\
\hline Stroke $(<24$ h) & $3(1.4 \%)$ & $1(0.46 \%)$ & .623 \\
\hline Stroke $(\geq 24 \mathrm{~h})$ & $4(1.8 \%)$ & $2(0.92 \%)$ & .685 \\
\hline $\begin{array}{l}\text { Transmural myocardial } \\
\text { infarction }\end{array}$ & 0 & 0 & 1.0 \\
\hline \multicolumn{4}{|l|}{ Mortality } \\
\hline Thirty-day mortality & $3(1.4 \%)$ & $6(2.8 \%)$ & .503 \\
\hline One-year mortality & $12(5.5 \%)$ & $10(4.6 \%)$ & .827 \\
\hline Discharge location & $(\mathrm{n}=204)$ & $(\mathrm{n}=202)$ & \\
\hline $\begin{array}{l}\text { Home with no nursing } \\
\text { services }\end{array}$ & $111(54.4 \%)$ & $135(66.8 \%)$ & .018 \\
\hline Home with nursing aide & $63(30.9 \%)$ & $52(25.7 \%)$ & \\
\hline Skilled nursing facility & $16(7.8 \%)$ & $5(2.5 \%)$ & \\
\hline $\begin{array}{l}\text { Short-term, acute } \\
\text { rehabilitation }\end{array}$ & $2(0.98 \%)$ & 0 & \\
\hline Other rehabilitation facility & $12(5.9 \%)$ & $10(5.0 \%)$ & \\
\hline Readmission & $(\mathrm{n}=205)$ & $(\mathrm{n}=207)$ & \\
\hline No readmissions within $1 \mathrm{y}$ & $177(86.3 \%)$ & $193(93.2 \%)$ & .023 \\
\hline$\geq 1$ readmission within $1 \mathrm{y}$ & $28(13.7 \%)$ & $14(6.8 \%)$ & \\
\hline Cardiac surgery & $3(10.7 \%)$ & $2(14.3 \%)$ & \\
\hline Pacemaker insertion & $4(14.3 \%)$ & $3(21.4 \%)$ & \\
\hline PCI & $4(14.3 \%)$ & $1(7.1 \%)$ & \\
\hline Arrhythmia & $6(21.4 \%)$ & $4(28.6 \%)$ & \\
\hline Chest pain or CHF & $6(21.4 \%)$ & $1(7.1 \%)$ & \\
\hline CVA/TIA & $2(7.1 \%)$ & $1(7.1 \%)$ & \\
\hline Pleural effusion & $3(10.7 \%)$ & $2(14.3 \%)$ & \\
\hline
\end{tabular}

Note that readmission subcategory percentages are based on the number of $\geq 1$ readmits. $P C I$, Percutaneous coronary intervention; $C H F$, congestive heart failure; $C V A$, cerebrovascular accident; TIA, transient ischemic attack.

had diabetes, $8.3 \%$ had a previous myocardial infarction, and $6 \%$ had a previous cerebrovascular accident. In addition to patient risk, hospital logistical factors such as bed availability and rehabilitation center transfer rates may result in hospital stay variability from one center to the next. Importantly, however, baseline risk did not differ among propensity matched groups and it is unlikely that logistical factors differentially affected one group versus the other in our analysis.

One of the early concerns with MIMVS was that a smaller incision would result in prolonged operative times and potentially increased resource use in the operating room. In our analysis, MIMVS was associated with an equivalent crossclamp time compared with ST and a mean bypass time that was longer by only 25 minutes. Despite this slightly longer bypass time, there was no significant difference in operating room costs between groups.

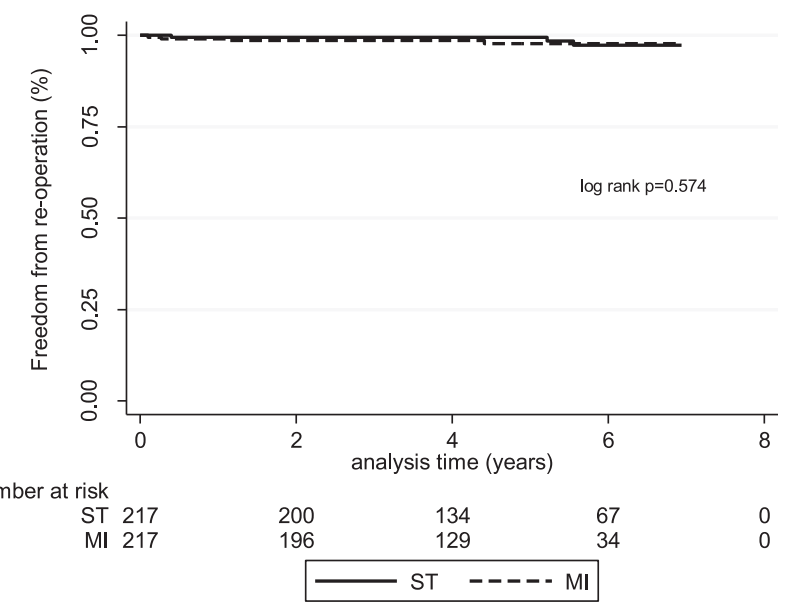

FIGURE 2. Freedom from mitral valve reoperation. $S T$, Sternotomy; $M I$, minimally invasive.

Traditional cost-effective analyses generally report the incremental cost-effectiveness ratio between 2 treatments as the difference in average cost divided by the difference in average effectiveness, often in the form of qualityadjusted life years. Inasmuch as our study was retrospective, no data on postoperative quality-adjusted life years was available. Furthermore, a literature search revealed no contemporary studies that have prospectively compared quality of life between MI and ST MVS. In the absence of such data, effectiveness could be analyzed from the perspective of valve integrity and freedom from reoperation. We found no difference in freedom from reoperation between groups, and these findings are consistent with other studies reporting freedom from reoperation rates ranging from $99.3 \%$ at 3.2 years to $91 \%$ at 4 years for MIMVS. ${ }^{30}$ Although long-term postoperative echocardiographic data were not available in our retrospective analysis, a recent study by Svensson and coworkers ${ }^{9}$ demonstrated no difference in the proportion of patients with mitral regurgitation grade $3+$ or $4+$ at 1 and 5 years when compared with the ST approach. ${ }^{9}$ Moreover, in our analysis there was no difference in morbidity, mortality, or long-term survival between groups. Therefore, on the basis of its lower cost and equivalent efficacy and safety relative to ST, our results suggest that MIMVS is cost-saving and cost-effective.

The cost savings associated with MIMVS could potentially be an underestimate in our analysis because we only included costs associated with the surgical admission. Further cost savings associated with MIMVS could be realized if the time horizon of our economic analysis was expanded to 1 year. More patients undergoing MIMVS were discharged home with no nursing services and fewer required transfer to rehabilitation facilities on discharge, representing significant cost savings. In addition, at 1 year the rate of hospital readmission for MI patients was half that of ST patients, which represents significant additional cost 
savings. Although the reasons for the observed lower readmission rate are an area of ongoing research, it is possible that improved functional status, as suggested by lower nursing and rehabilitation services, may facilitate overall recovery and prevent deconditioning associated with postoperative complications.

\section{Limitations}

There are several limitations to our analysis. First, our study is retrospective and subject to multiple potential biases. At our institution, the decision to pursue an MI approach involves an overall assessment of the feasibility and safety of such an approach based on the patient's preoperative risk. MIMVS is particularly challenging, for example, in patients with previous cardiac surgery, chronic obstructive pulmonary disease, and elevated body mass index, and this is reflected in the differences in baseline characteristics among unmatched pairs in Table 1. Although the $C$-statistic of our propensity score model demonstrated good model discrimination, selection bias cannot be completely eliminated through propensity matching. Also, it is possible that while 22 variables were considered in the propensity model, other risk factors may influence the selection to an MI versus an ST approach. Second, data on readmission and reoperation reflect only hospital readmissions that occurred at our institution. Therefore, a fraction of these events that occurred outside our hospital would not be included in the analysis. Nevertheless, it is unlikely that the rates of these occurrences at other institutions would have been different between groups. Last, our results do not take into account the potential effect of learning curves on clinical outcomes and the possibility that cost savings associated with MIMVS may not be realized early in the learning curve, or that overall cost savings associated with MIMVS may not be significant in magnitude at low-volume MVS centers.

\section{CONCLUSIONS}

MIMVS is a cost-effective and cost-saving strategy for mitral valve repair and replacement compared with the traditional ST approach with lower cost driven largely by a decreased length of stay. However, MIMVS demonstrated comparable efficacy across a range of efficacy measures such as freedom from reoperation, long-term survival, and in-hospital morbidity. As clinical trials emerge on the use of transcatheter mitral valve technologies and quality of life and cost become increasingly integrated into study end points, MIMVS may represent the standard on which to compare such emerging technologies.

\section{References}

1. Schmitto JD, Mokashi SA, Cohn LH. Minimally-invasive valve surgery. J Am Coll Cardiol. 2010;56:455-62.

2. McClure RS, Cohn LH, Wiegerinck E, Couper GS, Aranki SF, Bolman RM 3rd, et al. Early and late outcomes in minimally invasive mitral valve repair: an eleven-year experience in 707 patients. J Thorac Cardiovasc Surg. 2009;137: 70-5.

3. Gammie JS, Bartlett ST, Griffith BP. Small-incision mitral valve repair: safe, durable, and approaching perfection. Ann Surg. 2009;250:409-15.

4. Iribarne A, Karpenko A, Russo MJ, Cheema FH, Umann T, Oz MC, et al. Eightyear experience with minimally invasive cardiothoracic surgery. World J Surg. 2010;34:611-5.

5. Cohn LH, Adams DH, Couper GS, Bichell DP, Rosborough DM, Sears SP, et al. Minimally invasive cardiac valve surgery improves patient satisfaction while reducing costs of cardiac valve replacement and repair. Ann Surg. 1997;226:421-6; discussion 427-8.

6. Navia JL, Cosgrove DM. Minimally invasive mitral valve operations. Ann Thorac Surg. 1996;62:1542-4.

7. Chitwood WR Jr, Elbeery JR, Chapman WH, Moran JM, Lust RL, Wooden WA, et al. Video-assisted minimally invasive mitral valve surgery: the "micro-mitral" operation. J Thorac Cardiovasc Surg. 1997;113:413-4.

8. Falk V, Walther T, Autschbach R, Diegeler A, Battellini R, Mohr FW. Robotassisted minimally invasive solo mitral valve operation. J Thorac Cardiovasc Surg. 1998;115:470-1.

9. Svensson LG, Atik FA, Cosgrove DM, Blackstone EH, Rajeswaran J, Krishnaswamy G, et al. Minimally invasive versus conventional mitral valve surgery: a propensity-matched comparison. J Thorac Cardiovasc Surg. 2010;139: 926-32.

10. Walther T, Falk V, Metz S, Diegeler A, Battellini R, Autschbach R, et al. Pain and quality of life after minimally invasive versus conventional cardiac surgery. Ann Thorac Surg. 1999;67:1643-7.

11. Yamada T, Ochiai R, Takeda J, Shin H, Yozu R. Comparison of early postoperative quality of life in minimally invasive versus conventional valve surgery. $J$ Anesth. 2003;17:171-6.

12. Mihaljevic T, Cohn LH, Unic D, Aranki SF, Couper GS, Byrne JG. One thousand minimally invasive valve operations: early and late results. Ann Surg. 2004;240: 529-34.

13. Grossi EA, Galloway AC, Ribakove GH, Zakow PK, Derivaux CC, Baumann FG, et al. Impact of minimally invasive valvular heart surgery: a case-control study. Ann Thorac Surg. 2001;71:807-10.

14. Greelish JP, Cohn LH, Leacche M, Mitchell M, Karavas A, Fox J, et al. Minimally invasive mitral valve repair suggests earlier operations for mitral valve disease. J Thorac Cardiovasc Surg. 2003;126:365-71; discussion 371-3.

15. Aybek T, Dogan S, Risteski PS, Zierer A, Wittlinger T, Wimmer-Greinecker G, et al. Two hundred forty minimally invasive mitral operations through right minithoracotomy. Ann Thorac Surg. 2006;81:1618-24.

16. Galloway AC, Schwartz CF, Ribakove GH, Crooke GA, Gogoladze G, Ursomanno P, et al. A decade of minimally invasive mitral repair: long-term outcomes. Ann Thorac Surg. 2009;88:1180-4

17. Grossi EA, Galloway AC, Ribakove GH, Buttenheim PM, Esposito R, Baumann FG, et al. Minimally invasive port access surgery reduces operative morbidity for valve replacement in the elderly. Heart Surg Forum. 1999;2:212-5

18. Iribarne A, Russo MJ, Easterwood R. Minimally invasive versus sternotomy approach for mitral valve surgery, 2010 for mitral valve surgery: a propensity analysis. Ann Thorac Surg. 2010;90:1471-7; discussion 1477-8.

19. Chitwood WR Jr, Wixon CL, Elbeery JR, Moran JF, Chapman WH, Lust RM. Video-assisted minimally invasive mitral valve surgery. J Thorac Cardiovasc Surg. 1997;114:773-80.

20. Cosgrove DM 3rd, Sabik JF, Navia JL. Minimally invasive valve operations. Ann Thorac Surg. 1998;65:1535-8.

21. Apolito RA, Greenberg MA, Menegus MA, Lowe AM, Sleeper LA, Goldberger MH, et al. Impact of the New York State cardiac surgery and percutaneous coronary intervention reporting system on the management of patients with acute myocardial infarction complicated by cardiogenic shock. Am Heart J. 2008;155:267-73.

22. STS National Database. Spring 2003, Executive Summary. Durham (NC): Duke Clinical Research Institute; 2003.

23. Morgan JA, Thornton BA, Peacock JC, Hollingsworth KW, Smith CR, Oz MC, et al. Does robotic technology make minimally invasive cardiac surgery too expensive? A hospital cost analysis of robotic and conventional techniques. J Card Surg. 2005;20:246-51.

24. Barber JA, Thompson SG. Analysis and interpretation of cost data in randomised controlled trials, 1998 trials: review of published studies. BMJ. 1998;317: 1195-200.

25. Barber JA, Thompson SG. Analysis of cost data in randomized trials: an application of the non-parametric bootstrap. Stat Med. 2000;19:3219-36. 
26. Manning WG, Mullahy J. Estimating log models: to transform or not to transform? J Health Econ. 2001;20:461-94.

27. Iribarne A, Russo MJ, Moskowitz AJ, Ascheim DD, Brown LD, Gelijns AC. Assessing technological change in cardiothoracic surgery. Semin Thorac Cardiovasc Surg. 2009;21:28-34.

28. Iribarne A, Easterwood R, Russo MJ, Wang YC. Integrating economic evaluation methods into Clinical and Translational Science Award consortium comparative effectiveness educational goals. Acad Med. 2011;86:701-5.

29. Modi P, Hassan A, Chitwood WR Jr. Minimally invasive mitral valve surgery: a systematic review and meta-analysis. Eur J Cardiothorac Surg. 2008;34:943-52.

APPENDIX 1. Univariate analysis of variables considered for selection into logistic regression model to predict selection to MI versus ST

approach

\begin{tabular}{|c|c|c|c|}
\hline Variable & $\begin{array}{c}\text { Odds ratio } \\
\text { MI:ST }\end{array}$ & $95 \%$ CI & $\begin{array}{r}P \\
\text { valu } \\
\end{array}$ \\
\hline \multicolumn{4}{|l|}{ Patient baseline } \\
\hline Age & 0.974 & $0.965-0.984$ & $<.0$ \\
\hline BMI & 0.943 & $0.917-0.971$ & $<.00$ \\
\hline CVA & 0.406 & $0.231-0.712$ & .0 \\
\hline COPD & 0.522 & $0.290-0.940$ & .0 \\
\hline Creatinine & 0.522 & $0.290-0.940$ & . \\
\hline Current CHF & 0.353 & $0.252-0.495$ & $<.00$ \\
\hline Current smoker & 1.13 & $0.559-2.29$ & .7 \\
\hline Diabetes & 0.462 & $0.281-0.759$ & .0 \\
\hline Ejection fraction & 1.02 & $1.01-1.04$ & $<.00$ \\
\hline Gender (male) & 0.694 & $0.528-0.915$ & \\
\hline Hepatic failure & 0.697 & $0.043-11.18$ & .7 \\
\hline History of endocarditis & 0.375 & $0.124-1.14$ & .0 \\
\hline History of ventricular arrhythmias & 0.696 & $0.098-4.97$ & .7 \\
\hline Immune system deficiency & 0.241 & $0.106-0.549$ & .0 \\
\hline Peripheral vascular disease & 0.304 & $0.093-0.996$ & \\
\hline Previous myocardial infarction & 0.708 & $0.406-1.24$ & .2 \\
\hline Previous cardiac surgery & 0.161 & $0.104-0.249$ & $<.0$ \\
\hline Renal failure or dialysis & 0.096 & $0.022-0.425$ & .0 \\
\hline Vasodilatory shock preoperative) & 0.357 & $0.040-3.21$ & .3 \\
\hline \multicolumn{4}{|l|}{ Operative } \\
\hline Repair versus replacement & 6.37 & $4.68-8.66$ & $<.0$ \\
\hline Secondary minor procedure & 1.02 & $0.983-1.05$ & .3 \\
\hline Surgeon & 0.917 & $0.850-0.988$ & .02 \\
\hline
\end{tabular}

$M I$, Minimally invasive; $S T$, sternotomy; $C I$, confidence interval; $B M I$, body mass index; $C V A$, cerebrovascular accident; $C O P D$, chronic obstructive pulmonary disease; $C H F$, congestive heart failure.
30. Suri RM, Schaff HV, Meyer SR, Hargrove WC 3rd. Thoracoscopic versus open mitral valve repair: a propensity score analysis of early outcomes. Ann Thorac Surg. 2009;88:1185-90.

31. Adult Cardiac Surgery Database Executive Summary-Period Ending 06/30/ 2010. Available at: http://www.sts.org/sites/default/files/documents/pdf/ndb2010/ 3rdHarvestExecutiveSummary2010.pdf. Accessed March 20, 2011

32. Gammie JS, Zhao Y, Peterson ED, O'Brien SM, Rankin JS, Griffith BP. Less-invasive mitral valve operations: trends and outcomes from The Society of Thoracic Surgeons Adult Cardiac Surgery Database. Ann Thorac Surg. 2010;90: 1401-8.
APPENDIX 2. Final regression model used to generate propensity scores

\begin{tabular}{lccr}
\hline \multicolumn{1}{c}{ Risk factor } & $\begin{array}{c}\text { Odds ratio } \\
\text { MI:ST }\end{array}$ & $\mathbf{9 5 \% ~ C I ~}$ & $\begin{array}{c}\boldsymbol{P} \\
\text { value }\end{array}$ \\
\hline Age & 0.981 & $0.970-0.993$ & .002 \\
BMI & 0.940 & $0.909-0.972$ & $<.001$ \\
Current CHF & 0.565 & $0.372-0.856$ & .007 \\
Ejection fraction & 1.02 & $1.01-1.04$ & .019 \\
Immune system deficiency & 0.367 & $0.146-0.922$ & .033 \\
Previous cardiac surgery & 0.243 & $0.142-0.415$ & $<.001$ \\
Previous myocardial infarction & 2.12 & $1.04-4.33$ & .002 \\
Repair versus replacement & 4.65 & $3.26-6.62$ & $<.001$ \\
Renal failure or dialysis & 0.159 & $0.031-0.840$ & .007 \\
Secondary minor procedure & 0.962 & $0.921-0.997$ & .036 \\
\hline
\end{tabular}

$M I$, Minimally invasive; $S T$, sternotomy; $C I$, confidence interval; $B M I$, body mass index; $C H F$, congestive heart failure. 